Check for updates

Cite this: RSC Adv., 2021, 11, 12990

Received 9th March 2021

Accepted 30th March 2021

DOI: $10.1039 / \mathrm{d} 1 \mathrm{ra01858b}$

rsc.li/rsc-advances

\section{Green synthesis of new lawsone enaminones and their $Z / E(C=C)$-isomerization induced by organic solvent $\uparrow$}

\begin{abstract}
Abolfazl Olyaei, (D) * Amir Mohamadi and Nilufar Rahmani
The synthesis of a new class of lawsone enaminone derivatives by using lawsone, triethyl orthoformate and aromatic amines in the presence of guanidinium chloride under solvent-free conditions has been developed. Investigation of ${ }^{1} \mathrm{H}-\mathrm{NMR}$ spectra indicated that lawsone enaminones exist in the ketoenamine tautomeric form and undergo $Z / E$-isomerization with respect to the $\mathrm{C}=\mathrm{C}$ bond in $\mathrm{DMSO}-d_{6}$ at room temperature. Furthermore, intramolecular hydrogen bonds have been observed in the synthesized compounds. This method has some advantages including short reaction times, high to excellent yields, simple work-up procedure and very easy purification of products by non-chromatographic methods.
\end{abstract}

\section{Introduction}

Enaminone derivatives are versatile readily obtainable reagents and their chemistry has received considerable attention in recent years. They have demonstrated a potential as multipurpose synthetic intermediates in organic synthesis such as various heterocyclic compounds, ${ }^{1-5}$ synthons for the synthesis of various biologically active compounds such as antitumor, anti-epileptic, anti-inflammatory, antibacterial, anticonvulsant, and other therapeutic agents ${ }^{6-13}$ and also a substructure that frequently occurs in natural products. ${ }^{14}$ They can also be used as starting materials for the stereoselective preparation of $\gamma$-aminoalcohols (by reduction). ${ }^{15} \mathrm{~A}$ literature survey reveals the availability of numerous catalysts and methods for the synthesis of these compounds. The most important and straightforward method involves the direct condensation of $\beta$-dicarbonyl compounds with amines using various catalysts. ${ }^{16-20}$ Enaminones have a pronounced tendency to undergo various isomeric transformations in solvents with different polarities. This property is particularly important for applications of enaminones and plays a major role in determining chemical, biological, and therapeutic activities of these compounds. According to the ${ }^{1} \mathrm{H}$ - and ${ }^{13} \mathrm{C}$-NMR spectroscopy, they have feature intramolecular hydrogen bonds of $\mathrm{O}-\mathrm{H} \cdots \mathrm{N}$ and $\mathrm{N}-\mathrm{H} \cdots \mathrm{O}$ type, tautomerism between the enol imine and ketoenamine forms, and $Z / E$-isomerization of the ketoenamine form in respect to the $\mathrm{C}=\mathrm{C}$ bond. ${ }^{21}$

Department of Chemistry, Payame Noor University (PNU), PO BOX 19395-4697, Tehran, Iran. E-mail: Olyaei_a@pnu.ac.ir; Fax: +98-28-33374081; Tel: +98-2833376366

$\dagger$ Electronic supplementary information (ESI) available: Experimental procedures and characterization data of products, IR, ${ }^{1} \mathrm{H}-\mathrm{NMR}$ and mass. See DOI: 10.1039/d1ra01858b
2-Hydroxy-1,4-naphthoquinone, or lawsone, or hennotannic acid, is one of the simplest naturally occurring naphthoquinones and is useful for many applications in various scientific and technological fields. It has been used as the starting material for the synthesis of a variety of biologically active compounds and materials with interesting properties. ${ }^{22-25}$ In recent decades, it has been used in many reactions for the

Table 1 Optimization of reaction conditions for the synthesis of $4 a^{a}$

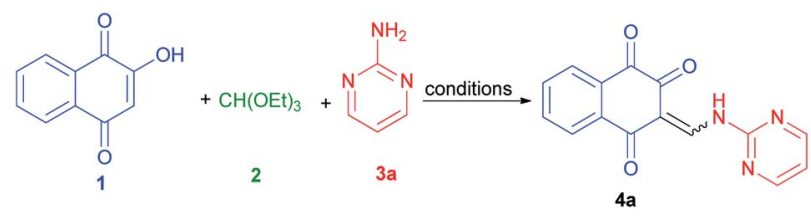

\begin{tabular}{llllll}
\hline Entry & Solvent & $\begin{array}{l}\text { Catalyst } \\
(\mathrm{mol} \%)\end{array}$ & $\begin{array}{l}\text { Temperature } \\
\left({ }^{\circ} \mathrm{C}\right)\end{array}$ & $\begin{array}{l}\text { Time } \\
(\mathrm{min})\end{array}$ & $\begin{array}{l}\begin{array}{l}E)^{b} \\
(\%)\end{array} \\
1\end{array}$ \\
\hline EtOH & 10 & Reflux & 90 & Trace \\
2 & $\mathrm{CH}_{3} \mathrm{CN}$ & 10 & Reflux & 90 & 45 \\
3 & $\mathrm{H}_{2} \mathrm{O}$ & 10 & Reflux & 90 & Trace \\
4 & THF & 10 & Reflux & 90 & Trace \\
5 & Neat & 10 & 70 & 40 & 78 \\
6 & Neat & 10 & 80 & 25 & 80 \\
7 & Neat & 10 & 90 & 15 & 85 \\
8 & Neat & - & 90 & 60 & 30 \\
9 & Neat & 5 & 90 & 25 & 75 \\
10 & Neat & 15 & 90 & 15 & 86 \\
11 & Neat & 20 & 90 & 15 & 86
\end{tabular}

${ }^{a}$ Reaction conditions: $1.0 \mathrm{mmol}$ of $1,1.0 \mathrm{mmol}$ of $2,1.0 \mathrm{mmol}$ of $3 \mathrm{a}$, solvent ( $5 \mathrm{ml}$ ), catalyst (guanidinium chloride). ${ }^{b}$ Isolated yield. 
synthesis of various organic compounds. ${ }^{26}$ Moreover, synthesis of aminonaphthoquinone Mannich base derivatives, as an interesting class of naphthoquinones, by multicomponent reactions of lawsone with a non-enolizable aldehyde and a primary or secondary amine via the Mannich reaction and their metal complexes using different conditions, and applications of these compounds has been reviewed. ${ }^{27}$

Considering the above points, and also in continuation of our interest on the synthesis of different kinds of heterocyclic compounds based on MCRs, ${ }^{28}$ herein we wish to report one-pot three-component synthesis of new lawsone enaminones from lawsone, triethyl orthoformate and aromatic amines in the presence of guanidinium chloride under solvent-free conditions and investigation of their $Z / E(\mathrm{C}=\mathrm{C})$-isomerization in DMSO- $d_{6}$ at room temperature by ${ }^{1} \mathrm{H}-\mathrm{NMR}$ spectroscopy. To the best of our knowledge, there are no reports available for the synthesis of lawsone enaminone derivatives in the literature.

\section{Results and discussion}

To find an appropriate reaction condition for the synthesis of lawsone enaminone derivatives, a one-pot three-component reaction between lawsone (1) $(1.0 \mathrm{mmol})$, triethyl orthoformate (2) (1.0 mmol) and 2-aminopyrimidine (3a) $(1.0 \mathrm{mmol})$ was selected as a model reaction and was studied by employing guanidinium chloride as organocatalyst. Initially, we commenced the above three-component reaction using protic and aprotic solvents such as ethanol, water, acetonitrile and tetrahydrofuran under reflux conditions in the presence of guanidinium chloride (10 $\mathrm{mol} \%$ ) as the catalyst. As indicated in Table 1, the reaction proceed in $\mathrm{CH}_{3} \mathrm{CN}$ and resulted the desired product $4 \mathrm{a}$ in $45 \%$ yield after $90 \mathrm{~min}$ (Table 1, entry 2). Moreover, the reaction couldn't proceed smoothly in $\mathrm{EtOH}, \mathrm{H}_{2} \mathrm{O}$ and THF after 90 min (Table 1, entries 1, 3 and 4). Increasing the reaction time did not improve the results. Then, we performed the same reaction under solvent-free conditions at $70,80,90{ }^{\circ} \mathrm{C}$, and observed that the reaction took place smoothly at $90{ }^{\circ} \mathrm{C}$, affording the desired product $4 \mathbf{a}$ in $85 \%$ yield at $15 \mathrm{~min}$ (Table 1 , entry 7). Thus, $90{ }^{\circ} \mathrm{C}$ was selected as the promising condition for further screening of the appropriate loading amount of catalyst $(0,5,15$ and $20 \mathrm{~mol} \%)$. When the reaction was performed under solvent and catalyst-free condition, the corresponding product 4a obtained in 30\% yield after $60 \mathrm{~min}$ (Table 1, entry 8). The reaction with $5 \mathrm{~mol} \%$ of the catalyst required a longer reaction time and produced only a $75 \%$ yield of the desired product $4 \mathbf{a}$ (Table 1, entry 9). Also, increasing the catalyst loading to 15 and $20 \mathrm{~mol} \%$ did not affect the progress of the reaction markedly. As a result, it was found that $10 \mathrm{~mol} \%$ of catalyst was enough to promote the reaction efficiently. Finally, the optimal conditions were determined as lawsone $(1.0 \mathrm{mmol})$, triethyl orthoformate (1.0 mmol) and 2-aminopyrimidine $(1.0 \mathrm{mmol})$ under solventfree condition at $90{ }^{\circ} \mathrm{C}$ for $15 \mathrm{~min}$.

With the optimized conditions in hand, the scope and generality of this protocol were next examined by employing various aromatic amines. As shown in Table 2, the reaction with different aryl/heteroaryl amines bearing electron-donating or electron-withdrawing substituents proceeded smoothly in 10$35 \mathrm{~min}$ to afford the desired products $\mathbf{4 a - k}$ in high to excellent yields (75-87\%). Meanwhile, we also found that the aromatic amines bearing electron-donating substituents such as methyl reacted rapidly, while those with bearing electron-withdrawing

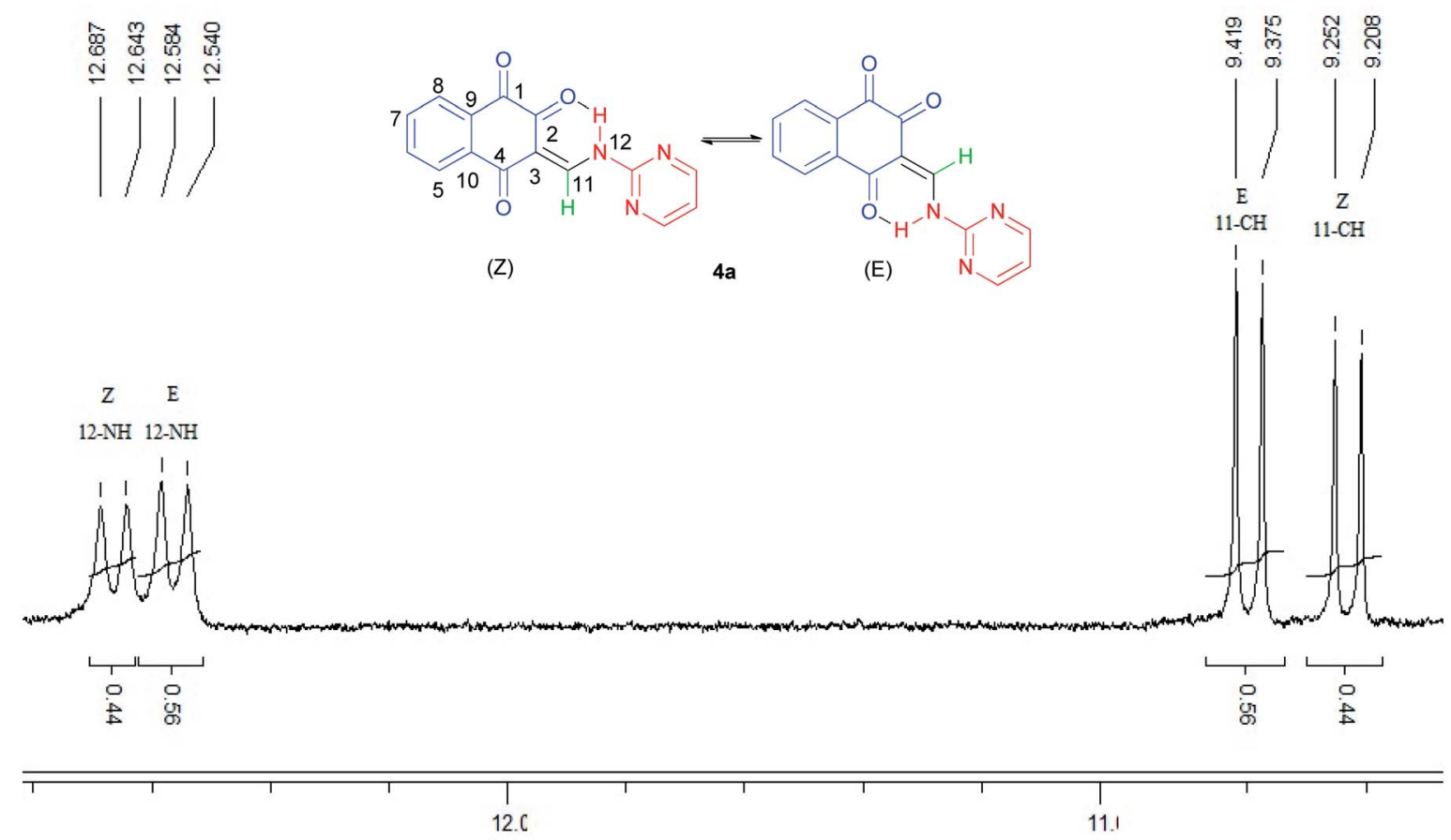

Fig. $1{ }^{1} \mathrm{H}-\mathrm{NMR}$ spectrum of compound $4 \mathrm{a}$. 
Table 2 Substrate scope for the synthesis of lawsone enaminone derivatives 4

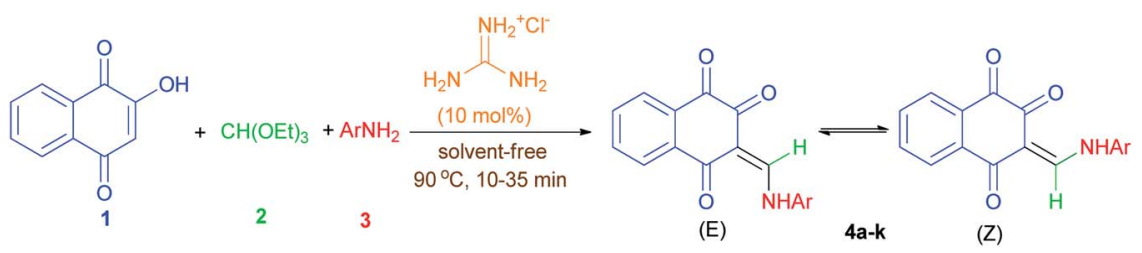

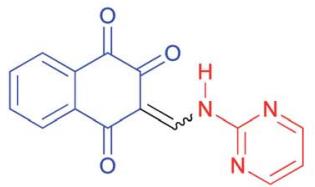

4a, $15 \min , E: Z=56: 44$<smiles>Cc1ccnc(NC=C2C(=O)C(=O)c3ccccc3C2=O)c1</smiles>

4d, 20 min, $E: Z=55: 45$

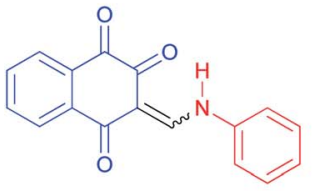

$4 g, 30 \min , E: Z=55: 45$<smiles>Cc1cc(C)nc(NC=C2C(=O)C(=O)c3ccccc3C2=O)n1</smiles>

4b, 10 min, $E: Z=55: 45$<smiles>Cc1cccc(NC=C2C(=O)C(=O)c3ccccc3C2=O)n1</smiles>

4e, $10 \min , E: Z=54: 46$<smiles>Cc1ccc(NC=C2C(=O)C(=O)c3ccccc3C2=O)cc1</smiles>

4h, $20 \min , E: Z=56: 44$<smiles>Cc1ccccc1NNC=C1C(=O)C(=O)c2ccccc2C1=O</smiles>

$4 c, 20 \min , E: Z=58: 42$<smiles>O=C1C(=O)c2ccccc2C(=O)C1=CNc1ccc(Br)cn1</smiles>

4f, $35 \min , E: Z=55: 45$<smiles>O=C1C(=O)c2ccccc2C(=O)C1=CNc1cccc(Cl)c1</smiles>

$4 i, 30 \min , E: Z=55: 45$

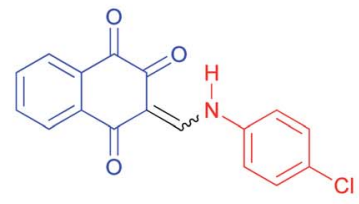

4j, 25 min, $E: Z=58: 42$

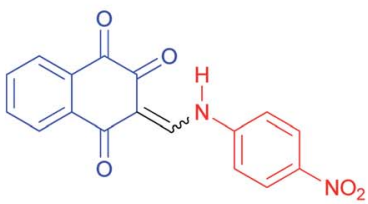

$4 k, 30 \min , E: Z=55: 45$ substituents such as chloro and nitro required longer reaction times, but products were obtained in comparable yields.

All isolated products were new and fully characterized based on their analytical data and detailed spectral studies including Fourier transform infrared (FT-IR), ${ }^{1} \mathrm{H}-\mathrm{NMR}$ and mass spectroscopy. Despite of heating the samples in DMSO- $d_{6}$ prior to ${ }^{13} \mathrm{C}-\mathrm{NMR}$ measurement, the low solubility of such compounds makes it difficult to receive a clean ${ }^{13} \mathrm{C}-\mathrm{NMR}$ spectrum.

The ${ }^{1} \mathrm{H}-\mathrm{NMR}$ spectra indicated that all of the synthesized compounds $4 \mathbf{4}-\mathbf{k}$ existed in DMSO- $d_{6}$ solution as a mixture of $E$ and $Z$-keto enamine isomers. For example, a characteristic feature of the ${ }^{1} \mathrm{H}-\mathrm{NMR}$ spectrum of compound $4 \mathrm{a}$ is the presence of two downfield signals corresponding to the protons of the $\mathrm{NH}$ group at 12.66 and $12.56 \mathrm{ppm}$. As indicated in Fig. 1, the more downfield signal corresponds to the $Z$-isomer of compound $\mathbf{4 a}$ which is stabilized by a strong chelate type intramolecular hydrogen bond with the oxygen of the $\mathrm{C}(2)=\mathrm{O}$ group. The signal for the proton of the $\mathrm{NH}$ group in the more upfield region corresponds to the $E$-isomer. The formation of another intramolecular hydrogen bond with oxygen atom of the $\mathrm{C}(4)=\mathrm{O}$ fragment is possible in this isomer. This hydrogen bond is significantly weaker than the hydrogen bond between the $12-\mathrm{NH}$ and $\mathrm{C}(2)=\mathrm{O}$ groups. Moreover, in the isomer $E$, due to the resonance of the electron-nitrogen pair with the $\mathrm{C}(2)=\mathrm{O}$, a $S$-trans structure is formed, which is more stable than the $S$-cis structure formed in the isomer $Z$ (Scheme 1). With such an assignment the integral intensities of the 12- $\mathrm{NH}$ signals allow quantitative determination of the corresponding isomer content in the equilibrium mixtures: the $Z$-isomer from the signal at $12.66 \mathrm{ppm}(44 \%)$ and the $E$-isomer from the signal at $12.56 \mathrm{ppm}$ (56\%). The difference between the 11-CH proton chemical shift values for the two geometric isomers is substantially smaller, and the 11-CH signal from the $Z$-isomer is located upfield. It is interesting to note the values of the vicinal 


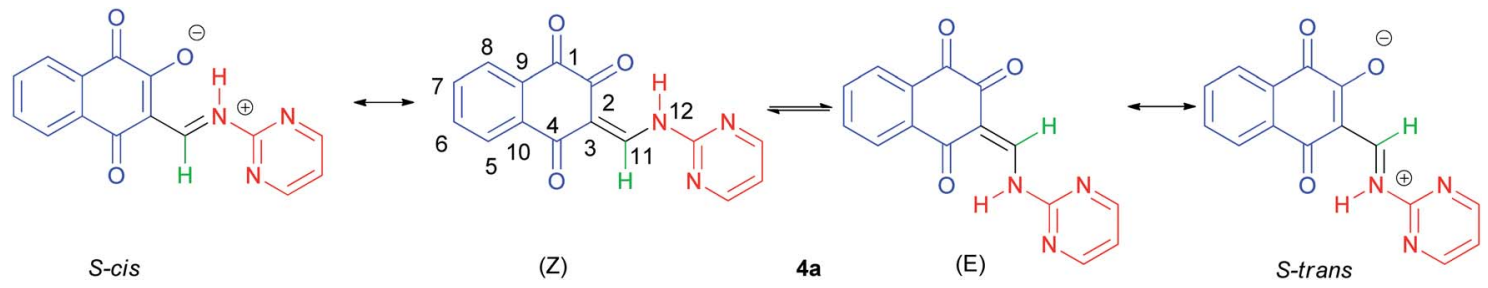

Scheme 1 Structures of compound $4 a$.

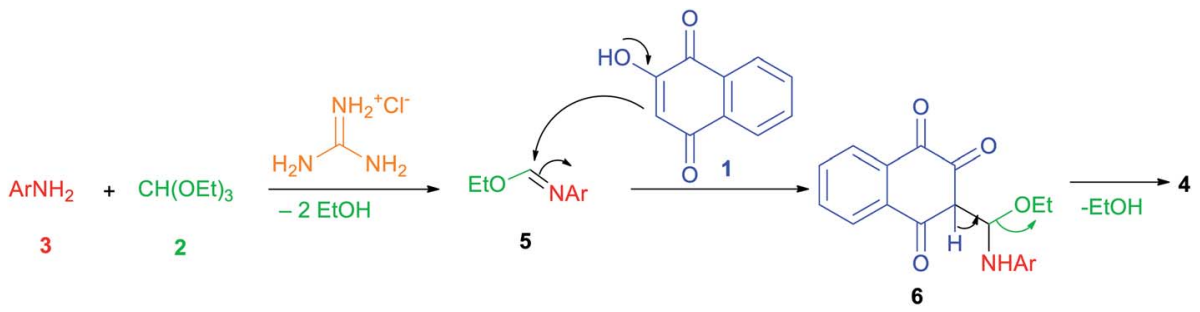

Scheme 2 Possible reaction mechanism.

spin-spin coupling constants $J_{11,12}$ of the $11-\mathrm{CH}$ and $12-\mathrm{NH}$ protons for the two isomeric forms are $13.2 \mathrm{~Hz}$, indicating a transoid arrangement of the $\mathrm{N}(12)-\mathrm{H}$ and $\mathrm{C}(11)-\mathrm{H}$ bonds. It should be noted that there is no signal of hydroxyimine tautomer in the ${ }^{1} \mathrm{H}$-NMR spectra of the synthesized compounds. In the IR spectrum of compound $\mathbf{4 a}$, the sharp peaks at 3397, 1690,1665 and $1608 \mathrm{~cm}^{-1}$ are due to the stretching frequencies of $\mathrm{N}-\mathrm{H}$ and $\mathrm{C}=\mathrm{O}$, respectively. The $E: Z$ ratio of isomers $4 \mathbf{a}-\mathbf{k}$ are listed in Table 2.

The plausible mechanism that could be accounted for this three-component reaction is depicted in Scheme 2. Firstly, the reaction proceeds through the in situ formation of intermediate 5 by the nucleophilic addition of amine $\mathbf{3}$ to triethyl orthoformate (2) which lose two molecules of EtOH in the presence of guanidine hydrochloride as catalyst. Subsequently lawsone (1) reacts with imine 5 to form another intermediate 6 which undergoes elimination of another $\mathrm{EtOH}$ molecule to give the desired product 4 .

\section{Conclusions}

In conclusion, we presented an environmentally benign synthetic and one-pot protocol for the synthesis of lawsone enaminone derivatives in high to excellent yields via the threecomponent reactions of lawsone, triethyl orthoformate and aromatic amines in the presence of guanidinium chloride under solvent-free condition at $90{ }^{\circ} \mathrm{C}$. ${ }^{1} \mathrm{H}$-NMR spectra of synthetic compounds indicated that lawsone enaminones exist in the ketoenamine tautomeric form and undergo $Z / E$-isomerization in respect to the $\mathrm{C}=\mathrm{C}$ bond in DMSO- $d_{6}$ at room temperature. Moreover, the attractive features of this protocol are simple reaction procedure, short reaction time, easy product separation, simple purification, high to excellent yields of products and this is the first report on the synthesis of lawsone enaminones.

\section{Conflicts of interest}

There are no conflicts to declare.

\section{Acknowledgements}

The authors thank the Research Council of Payame Noor University for financial support.

\section{References}

1 Y. Huang and R. W. Hartmann, Synth. Commun., 1998, 28, 1197-1200.

2 C. Balakrishna, R. Gudipati, V. Kandula, S. Yennam, P. U. Devi and M. Behera, New J. Chem., 2019, 43, 2458-2463.

3 C. P. Cartaya-Marin, D. G. Henderson and R. W. Soeder, Synth. Commun., 1997, 27, 4275-4283.

4 Z. Yang, L. Hu, T. Cao, L. An, L. Li, T. Yang and C. Zhou, New J. Chem., 2019, 43, 16441-16444.

5 N. D. Eddington, D. S. Cox, R. R. Roberts, J. P. Stables, C. B. Powell and K. R. Scott, Curr. Med. Chem., 2000, 7, 417-436.

6 I. O. Edafiogho, K. V. V. Ananthalakshmi and S. B. Kombian, Bioorg. Med. Chem., 2006, 14, 5266-5272.

7 M. Khurana, N. N. Salama, K. R. Scott, N. N. Nemieboka, K. S. Bauer and N. D. Eddington, Biopharm. Drug Dispos., 2003, 24, 397-407.

8 Y. F. Wang, T. Izawa, S. Kobayashi and M. Ohno, J. Am. Chem. Soc., 1982, 104, 6465-6466.

9 J. P. Michael, C. B. De Koning, G. D. Hosken and T. V. Stanbury, Tetrahedron, 2001, 57, 9635-9648.

10 I. O. Edafiogho, M. S. Alexander, J. A. Moore, V. A. Farrar and K. R. Scott, Curr. Med. Chem., 1994, 1, 159-175.

11 D. L. Boger, T. Ishizaki, R. J. Wysocki, S. A. Munk, P. A. Kitos and O. Suntornwat, J. Am. Chem. Soc., 1989, 111, 6461-6463. 
12 J. D. White and D. C. Ihle, Org. Lett., 2006, 8, 1081-1084. 13 I. O. Edafiogho, S. B. Kombian, K. V. V. Ananthalakshmi, N. N. Salama, N. D. Eddington, T. L. Wilson, M. S. Alexander, P. L. Jackson, C. D. Hanson and K. R. Scott, J. Pharm. Sci., 2007, 96, 2509-2531.

14 H. Zang and K. S. Gates, Biochemistry, 2000, 39, 1496814975.

15 C. Cimarelli, G. Palmieri and E. Volpini, Tetrahedron Lett., 2004, 45, 6629-6631.

16 J. V. Greenhill, Chem. Soc. Rev., 1977, 6, 277-294.

17 B. Govindh, B. S. Diwakar and Y. L. N. Murthy, Org. Commun., 2012, 5, 105-119.

18 A. E. Filkale and C. Pathak, New J. Chem., 2020, 44, 1510915121.

19 H. M. Gaber, M. C. Bagley, Z. A. Muhammad and S. M. Gomha, RSC Adv., 2017, 7, 14562-14610.

20 A. Z. A. Elassar and A. A. El-Khair, Tetrahedron, 2003, 59, 8463-8480.

21 V. F. Traven, I. V. Ivanov, V. S. Lebedev, B. G. Milevskii, T. A. Chibisova, N. P. Soloveva, V. I. Polshakov, O. N. Kazheva, G. G. Alexandrov and O. A. Dyachenko, Mendeleev Commun., 2009, 19, 214-216.

22 A. K. Jordão, M. D. Vargas, A. C. Pinto, F. d. C. da Silva and V. F. Ferreira, $R S C A d v$., 2015, 5, 67909-67943.

23 S. R. Patil, A. S. Choudhary and N. Sekar, New J. Chem., 2016, 40, 6803-6811.
24 D. Choudhari, S. Salunke-Gawali, D. Chakravarty, S. R. Shaikh, D. N. Lande, S. P. Gejji, P. K. Rao, S. Satpute, V. G. Puranik and R. Gonnade, New J. Chem., 2020, 44, 6889-6901.

25 A. da R. Louvis, N. A. A. Silva, F. S. Semaan, F. d. C. da Silva, G. Saramago, L. C. S. V. de Souza, B. L. A. Ferreira, H. C. Castro, J. P. Salles, A. L. A. Souza, R. X. Faria, V. F. Ferreira and D. d. L. Martins, New J. Chem., 2016, 40, 7643-7656.

26 A. K. Jordao, M. D. Vargas, A. C. Pinto, F. d. C. da Silva and V. F. Ferreira, RSC Adv., 2015, 5, 67909-67943.

27 A. Olyaei, M. Sadeghpour and M. Khalaj, RSC Adv., 2020, 10, 30265-30281.

28 (a) A. Olyaei, M. S. Shahsavari and M. Sadeghpour, Res. Chem. Intermed., 2018, 44, 943-956; (b) A. Olyaei, R. Mohammad Ebrahimi, A. Adl and M. Sadeghpour, Chem. Heterocycl. Compd., 2019, 55, 1104-1110; (c) F. Noruzian, A. Olyaei and R. Hajinasiri, Res. Chem. Intermed., 2019, 45, 4383-4394; (d) R. Khoeiniha, A. Olyaei and M. Saraei, J. Heterocycl. Chem., 2017, 54, 1746-1750; (e) R. Khoeiniha, A. Olyaei and M. Saraei, Synth. Commun., 2018, 48, 155-160; (f) A. Olyaei, H. Ramezanipour Moghadam and M. Sadeghpour, J. Heterocycl. Chem., 2020, 57, 3029-3036; $(g)$ A. Olyaei, S. Javarsineh and M. Sadeghpour, Chem. Heterocycl. Compd., 2018, 54, 934939. 